\title{
Changes in left atrioventricular valve geometry after surgical repair of complete atrioventricular canal
}

\author{
Elisabeth Kaza, MD, Gerald R. Marx, MD, Aditya K. Kaza, MD, Steven D. Colan, MD, Hugo Loyola, MS, \\ Douglas P. Perrin, PhD, and Pedro J. del Nido, MD
}

Objective: The most common reason for late surgical reintervention after repair of complete atrioventricular canal defects is the development of left atrioventricular valve regurgitation. We sought to determine the changes in left atrioventricular valve geometry after surgical repair that may predispose to regurgitation.

\begin{abstract}
Methods: Atrioventricular valve measurements were obtained by 2-dimensional echocardiography at 3 different time points (preoperative, early postoperative, and midterm postoperative [6-12 months]). Left atrioventricular valve annulus area and left ventricular volume were calculated; vena contracta of the regurgitant jet orifice was measured. All measurements were normalized relative to an appropriate power of body surface area.
\end{abstract}

Results: From January 2000 to January 2008, 101 patients with complete atrioventricular canal repair were included. Left atrioventricular valve annulus was noted to remodel from an elliptical shape to a circular shape after surgery. Left atrioventricular valve annulus area increased early postoperatively (systole: $4.1 \pm 0.2 \mathrm{~cm}^{2} / \mathrm{m}^{2}$ vs $6.1 \pm 0.3 \mathrm{~cm}^{2} / \mathrm{m}^{2}, P<.001$; diastole: $7.2 \pm 0.4 \mathrm{~cm}^{2} / \mathrm{m}^{2}$ vs $10.0 \pm 0.5 \mathrm{~cm}^{2} / \mathrm{m}^{2}, P<.001$, pre- vs postoperative, respectively). This increase was sustained in the midterm postoperative period (systole: $6.1 \pm 0.3 \mathrm{~cm}^{2} / \mathrm{m}^{2}$, $P=.85$, vs diastole: $10.0 \pm 0.4 \mathrm{~cm}^{2} / \mathrm{m}^{2}, P=.78$, early vs midterm postoperative). Left ventricular volume increased in the early and midterm postoperative periods compared with preoperative (systole: $16.9 \pm 1.2 \mathrm{~mL} / \mathrm{m}^{2}$ vs $26.2 \pm 1.7 \mathrm{~mL} / \mathrm{m}^{2}, P<.001$; diastole: $35.0 \pm 2.4 \mathrm{~mL} / \mathrm{m}^{2}$ vs $52.5 \pm 3.2 \mathrm{~mL} / \mathrm{m}^{2}, P<.001$ ).

Conclusions: Complete atrioventricular canal repair leads to left atrioventricular valve annular shape change with increased area and circular shape. The change in left atrioventricular valve annulus shape appeared to be mainly due to increased circumference in the posterior free wall of the annulus. These findings may provide a mechanism for the progression of central regurgitation seen after complete atrioventricular canal repair and a potential solution. (J Thorac Cardiovasc Surg 2012;143:1117-24)

Atrioventricular (AV) canal defects are one of the more complex congenital heart lesions. They involve the AV valves and the ventricular and atrial septa. They range from an ostium primum atrial septal defect to the complete atrioventricular canal form (CAVC) with evidence of ostium primum atrial septal defect, a common AV valve, and a hemodynamically significant deficiency of the ventricular septum.

Surgical repair includes partitioning the common AV valve into the right- and left-sided components, closure of the valvar cleft or zone of apposition, and closure of any ventricular or atrial septal defects. ${ }^{1}$ Since the first successful repair of a CAVC by Lillehei and colleagues in $1954,{ }^{2} \mathrm{im}-$ proved technical methods and postoperative management

\footnotetext{
From the Division of Cardiac Surgery and Cardiology, Children's Hospital Boston and Harvard Medical School, Boston, Mass.

Disclosures: Authors have nothing to disclose with regard to commercial support.

Received for publication Jan 3, 2011; revisions received March 7, 2011; accepted for publication June 7, 2011; available ahead of print Nov 14, 2011.

Address for reprints: Pedro J. del Nido, MD, Division of Cardiac Surgery, Children's Hospital Boston, 300 Longwood Avenue, Bader 279, Boston, MA 02115 (E-mail: pedro.delnido@cardio.chboston.org).

$0022-5223 / \$ 36.00$

Copyright (c) 2012 by The American Association for Thoracic Surgery

doi:10.1016/j.jtcvs.2011.06.044
}

have resulted in declining mortality over time from approximately $50 \%$ to $2.5 \%$ to $13 \%{ }^{3-5}$ However, the incidence of $A V$ valve regurgitation after surgical correction remains the most common reason for repeat surgical intervention. In fact, hemodynamically significant left atrioventricular valve (LAVV) regurgitation is the main cause of early and late deaths, and need for reoperation. ${ }^{6,7}$ Although several factors have been related to postoperative LAVV regurgitation, there is limited information regarding the structure and geometry of the valve after repair and little analysis of geometric changes that may predispose to regurgitation. ${ }^{8-10}$ The observation that different surgical techniques are not associated with different outcomes reinforces the fact that we do not completely understand the pathophysiology of this complication as it relates to LAVV annular remodeling and postoperative leaflet motion. ${ }^{11,12}$ In this study, we sought to determine the changes in LAVV geometry after surgical repair using echocardiographic imaging and quantification, which may predispose to regurgitation postoperatively.

\section{PATIENTS AND METHODS}

The study was conducted in accordance with Institutional Human Subjects Committee guidelines and was approved by the institutional review board at Children's Hospital Boston. The study was a retrospective review 


$$
\begin{aligned}
& \text { Abbreviations and Acronyms } \\
& \begin{aligned}
\text { AV } & =\text { atrioventricular } \\
\text { BSA } & =\text { body surface area } \\
\text { CAVC } & =\text { complete atrioventricular canal form } \\
\text { LAVV } & =\text { left atrioventricular valve } \\
\text { LV } & =\text { left ventricular } \\
\text { 2D } & =2 \text {-dimensional } \\
\text { VC } & =\text { vena contracta }
\end{aligned}
\end{aligned}
$$

of the cardiology/cardiac surgery database at Children's Hospital Boston identifying all patients who underwent surgical repair for CAVC from January 2000 to January 2008. This time period was chosen because it includes a sufficiently large cohort of patients to permit meaningful statistical comparisons and because the surgical techniques did not vary greatly during this time period. The diagnosis was based on echocardiographic evidence of ostium primum atrial septal defect, a common $\mathrm{AV}$ valve and a hemodynamically significant deficiency of the ventricular septum. Children with transitional AV canal defects and isolated inlet ventricular septal defects were excluded from the study. Preoperative evaluation of the CAVC was done with 2-dimensional (2D) echocardiography and additional testing as warranted by the individual patient. Three different time points for echocardiography were used for the study. The first was the immediate preoperative study, the second was the early postoperative study (7-10 days after surgery), and the third was a midterm postoperative follow-up study (6-12 months after surgery). Parents of patients in whom the third echocardiography was not performed at Children's Hospital Boston were contacted, and informed consent was obtained to permit analysis of the midterm postoperative follow-up echocardiographic data that were obtained at an outside facility. Patients with missing postoperative echocardiographic data were excluded from the study. Patients with associated complex cardiac anomalies, such as transposition of the great arteries, tetralogy of Fallot, double-outlet right ventricle, and heterotaxy syndrome, were excluded from the study. All echocardiographic studies were reviewed by 1 echocardiographer (E.K.), and the measurement methodology was reviewed by 2 separate echocardiographers (G.M. and S.C.).

\section{Echocardiographic Measurements}

The common AV valve measurements obtained from the 2D echocardiography studies are shown in Figure 1. All measurements were performed at both end systole and end diastole. End systole is taken as the frame preceding LAVV opening. End diastole is taken as the frame at which the LAVV begins to close, which is the onset of isovolumic systole. The long-axis parasternal and apical 4-chamber views were used for all measurements (Figure 1, A). $A$ is the distance from the hinge point of the LAVV to the lowest extent of the atrial septum, $B$ is the distance from the hinge point of the right $\mathrm{AV}$ valve to the lowest extent of the atrial septum, $C$ is the transverse dimension of the common AV valve annulus, $D$ is the distance from the ventricular crest to the lowest extent of the atrial septum, $E$ and $G$ are the distances from the hinge points of the AV valves to the ventricular septal crest, $F$ is the length of the left ventricle from the plane of the common AV valve annulus to the apex of the left ventricle, and $I$ characterizes the anteroposterior diameter of the LAVV annulus obtained from the parasternal long-axis view. All measurements were normalized relative to an appropriate power of the body surface area (BSA), ${ }^{13}$ which was calculated at the time of surgery or early postoperative period and the midterm postoperative period. All values reported are normalized values, not raw measurements. Normalized dimensions are presented in "centimeters/meters," normalized areas are presented in "centimeters squared/meters squared," and normalized volumes are presented in "milliliters/meters cubed."
LAVV annulus area was determined using the formula for an ellipse, $(\mathrm{E} / 2) \cdot(\mathrm{I} / 2) \cdot 3.14$, and indexed to BSA. Left ventricular $(\mathrm{LV})$ volume was calculated by using the area-length method where the LV is assumed to be bullet-shaped. ${ }^{14}$ The mid-LV cross-sectional area was computed at a point one half the length of the left ventricle taken from the apex to the midpoint of the annulus in the apical 4-chamber view, and planimetry of the parasternal short-axis view at that level was done. These measurements were performed at end systole and end diastole, and the volume was computed according to the following formula: $\mathrm{LV}$ volume $=[(5 / 6) \cdot \mathrm{LAVV}$ annulus area $\cdot$ LV length]. LV length was determined by measurement F. For indexing LV volumes, we used the patient's BSA in square meters.

The ratio of $E$ over $I$ was used as a surrogate to determine the eccentricity of the LAVV. The vena contracta (VC) of the regurgitant jet orifice was measured as a semiquantitative estimate of the severity of LAVV regurgitation. Several studies have shown the accuracy and reproducibility of the $\mathrm{VC}$ width as a marker of left AV valve regurgitation in humans. All measurements were obtained on the echocardiograms of all enrolled patients at all 3 time points (preoperative, early postoperative, and midterm postoperative).

\section{Statistical Analysis}

Data are presented as mean \pm standard deviation/standard error of the mean or as median, unless otherwise specified. Generalized estimating equation analysis was used as implemented in STATA/IC 10.1 (StataCorp, College Station, Tex). From generalized estimating equation analysis, differences in normalized (indexed to BSA) measurements were evaluated over time.

\section{RESULTS \\ Study Cohort}

Between January 2000 and January 2008, 101 patients with AV canal repair (median age, 3.8 months; range, 6 days to 7 years) were included in this study. A total of 242 AV canal repairs were performed during this period at Children's Hospital Boston; however, only 101 patients were included in this study. The remaining patients had to be excluded because echocardiography studies were not available at all 3 time points. An additional 10 patients $(2.4 \%)$ died in the midterm follow-up period and were not included in the analysis. The operative mortality of patients included in this study was $0.82 \%$. The techniques for surgical repair of complete AV canal used in this study were the single patch ( $9 \%$ of patients), 2 patch $(80.6 \%$ of patients), and Australian (no ventricular septal defect patch) (10.4\% of patients). There was no relationship found between the type of surgical repair and the echocardiogram dimensions. Thirty-eight male $(37.6 \%)$ and 63 female $(62.4 \%)$ patients were identified in this study. Fifty-four patients were identified as having Down syndrome (55\%). The median age and weight of patients at the time of surgery were 3.8 months and $3.1 \mathrm{~kg}$, respectively. BSA calculated in the midterm postoperative period $(0.38 \pm 0.09 \mathrm{~cm})$ was significantly higher than calculated at the time of surgery or early postoperative period $(0.27 \pm 0.07 \mathrm{~cm}, P<.001)$.

\section{Echocardiographic Measurements}

All measurements made from the apical 4-chamber and parasternal long-axis views (Figure 1), including mean, 

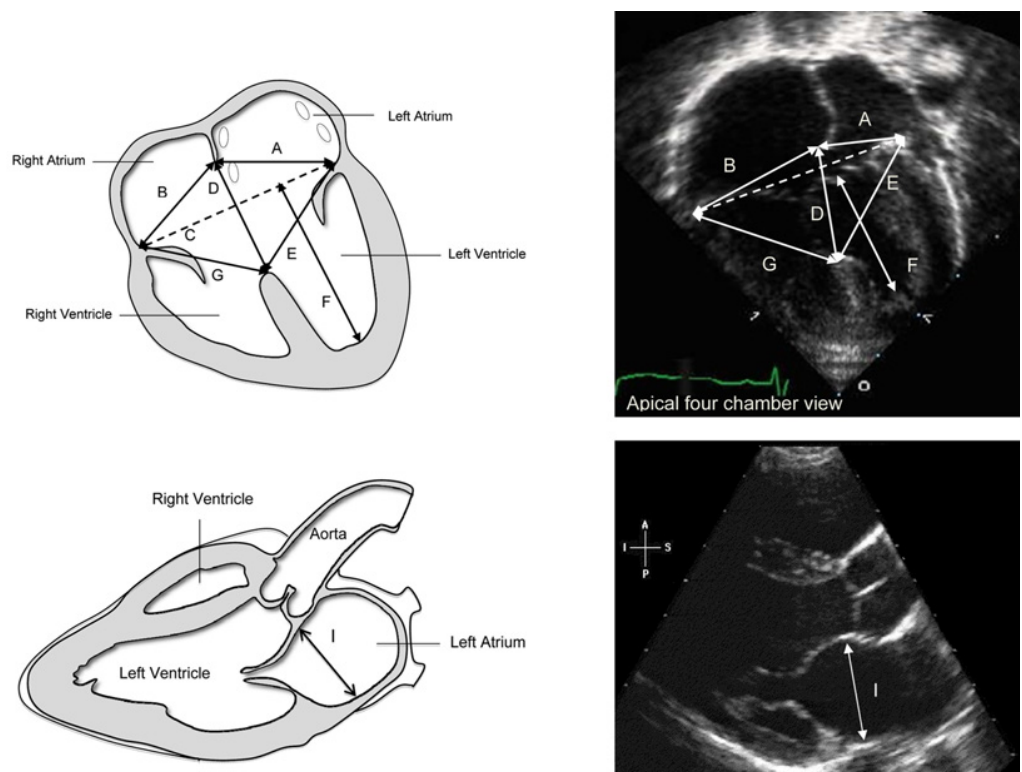

A

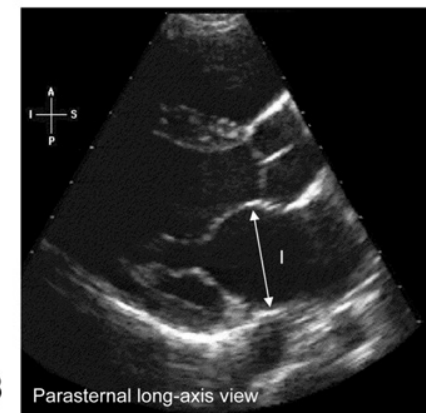

FIGURE 1. A, B, Various echocardiographic measurements taken in apical 4-chamber and parasternal long-axis views. $A$ is the distance from the hinge point of the left atrioventricular valve to the lower extent of the atrial septum. $B$ is the distance from the hinge point of the right atrioventricular valve to the lowest extent of the atrial septum, $C$ is the transverse dimension of the common atrioventricular valve annulus, and $D$ is the distance from the ventricular crest to the lowest extent of the atrial septum. $E$ and $G$ are distances from the hinge points of the atrioventricular valves to the ventricular septal crest, $F$ is the length of the left ventricle from the plane of the common atrioventricular valve annulus to the apex of the left ventricle, and $I$ characterizes the anteroposterior diameter of the left atrioventricular valve annulus obtained from the parasternal long-axis view.

standard deviation, and change over time, are shown in Tables 1 and 2. Figure $1, B$, shows representative $2 \mathrm{D}$ echocardiogram images with the specific measurements labeled.

$I$, which is the anteroposterior diameter of the LAVV annulus obtained from the parasternal long-axis view, was the parameter that showed the most significant increase from pre- to postoperative studies (Figure 2). This increase was evident in the early postoperative period and was sustained in the midterm postoperative follow-up period. The preoperative measurements were $1.6 \pm 0.5 \mathrm{~cm} / \mathrm{m}$ in systole and $2.5 \pm 0.5 \mathrm{~cm} / \mathrm{m}$ in diastole, the early postoperative measurements were $2.1 \pm 0.6 \mathrm{~cm} / \mathrm{m}$ in systole and $3.1 \pm 0.6 \mathrm{~cm} / \mathrm{m}$ in diastole, and the midterm postoperative measurements were $2.1 \pm 0.5 \mathrm{~cm} / \mathrm{m}$ in systole and $3.1 \pm 0.6 \mathrm{~cm} / \mathrm{m}$ in diastole. The increase in $I$ from preoperative to early postoperative period was an average of $0.5 \mathrm{~cm} / \mathrm{m}(95 \%$ confidence interval, 0.39-0.62) in systole and $0.6 \mathrm{~cm} / \mathrm{m}(95 \%$ confidence interval, $0.46-0.69)$ in diastole $(P<.001$ for systole and diastole comparisons). The increase in $I$ from preoperative to midterm postoperative period was similar to that seen early after surgery $(P<.001)$.

\section{Additional Echocardiographic Measurements}

$A$, which is the distance from the hinge point of the LAVV to the lowest extent of the atrial septum in the apical 4-chamber view, was significantly increased in the early postoperative echocardiogram compared with the preoperative echocardiogram in systole $(0.4 \pm 0.1 \mathrm{~cm} / \mathrm{m}, P<.001)$ and diastole $(0.7 \pm 0.1 \mathrm{~cm} / \mathrm{m}, P<.001)$. There was no further increase seen in $A$ in the midterm postoperative echocardiogram in systole.

There were no changes in $B, D$, and $G$ from the preoperative period to the early postoperative period in both systole and diastole (Table 1). These measurements were also unchanged in the midterm postoperative period.

$C$, the distance between the left and the right AV valve annulus in the apical 4-chamber view, increased significantly in the early postoperative period compared with the preoperative period (systole: $0.3 \pm 0.1 \mathrm{~cm} / \mathrm{m}, P=.025$; diastole: $0.5 \pm 0.1 \mathrm{~cm} / \mathrm{m}, P<.001)$. The lack of change in the rightsided measurements $B, D$, and $G$ during the same time period implies that most of the change in $C$, which occurred postoperatively, was due to changes in the left side of the $\mathrm{AV}$ valve as seen in the apical 4-chamber view.

$E$, the length of the $\mathrm{LV}$ as seen on the apical 4-chamber view, also increased in the early postoperative echocardiogram when compared with the preoperative study (systole: $0.4 \pm 0.1 \mathrm{~cm} / \mathrm{m}, P<.001$; diastole: $0.5 \pm 0.1 \mathrm{~cm} / \mathrm{m}$, $P<.001)$. There was no further increase in $E$ in the midterm postoperative echocardiogram (systole: $0.01 \pm 0.1 \mathrm{~cm} / \mathrm{m}$, $P=.879$; diastole: $0.02 \pm 0.1 \mathrm{~cm} / \mathrm{m}, P=.875)$. 
TABLE 1. Pre- and postoperative atrioventricular valve dimensions

\begin{tabular}{|c|c|c|c|c|}
\hline & \multicolumn{2}{|c|}{ Systole } & \multicolumn{2}{|c|}{ Diastole } \\
\hline & $\mathbf{c m} / \mathbf{m}$ & SD & $\mathbf{c m} / \mathbf{m}$ & SD \\
\hline \multicolumn{5}{|l|}{$A$} \\
\hline Preoperative (T1) & 2.7 & 0.8 & 2.4 & 0.7 \\
\hline Early postoperative (T2) & 3.1 & 0.7 & 3.0 & 0.7 \\
\hline Midterm postoperative (T3) & 3.2 & 0.7 & 3.1 & 0.7 \\
\hline \multicolumn{5}{|l|}{$B$} \\
\hline Preoperative (T1) & 3.6 & 0.9 & 3.5 & 0.9 \\
\hline Early postoperative (T2) & 3.4 & 0.9 & 3.3 & 0.8 \\
\hline Midterm postoperative (T3) & 3.2 & 0.8 & 3.2 & 0.8 \\
\hline \multicolumn{5}{|l|}{ C } \\
\hline Preoperative (T1) & 5.9 & 1.2 & 5.7 & 1.4 \\
\hline Early postoperative (T2) & 6.2 & 1.2 & 6.2 & 1.3 \\
\hline Midterm postoperative (T3) & 6.2 & 1.2 & 6.3 & 1.2 \\
\hline \multicolumn{5}{|l|}{$D$} \\
\hline Preoperative (T1) & 2.7 & 0.8 & 4.9 & 0.3 \\
\hline Early postoperative (T2) & 2.6 & 0.8 & 2.7 & 0.6 \\
\hline Midterm postoperative (T3) & 2.5 & 0.7 & 2.6 & 0.6 \\
\hline \multicolumn{5}{|l|}{ E } \\
\hline Preoperative (T1) & 3.3 & 0.7 & 3.5 & 0.8 \\
\hline Early postoperative (T2) & 3.7 & 0.8 & 4.0 & 0.8 \\
\hline Midterm postoperative (T3) & 3.7 & 0.8 & 4.1 & 0.8 \\
\hline \multicolumn{5}{|l|}{$F$} \\
\hline Preoperative (T1) & 4.8 & 1.0 & 5.7 & 1.0 \\
\hline Early postoperative (T2) & 5.0 & 1.0 & 6.2 & 1.0 \\
\hline Midterm postoperative (T3) & 5.2 & 1.0 & 6.2 & 0.9 \\
\hline \multicolumn{5}{|l|}{$G$} \\
\hline Preoperative (T1) & 4.0 & 0.8 & 4.0 & 1.0 \\
\hline Early postoperative (T2) & 3.9 & 0.9 & 4.1 & 0.9 \\
\hline Midterm postoperative (T3) & 3.6 & 0.9 & 3.9 & 0.8 \\
\hline \multicolumn{5}{|l|}{ Cla } \\
\hline Preoperative (T1) & 1.6 & 0.5 & 2.5 & 0.5 \\
\hline Early postoperative (T2) & 2.1 & 0.6 & 3.1 & 0.6 \\
\hline Midterm postoperative (T3) & 2.1 & 0.5 & 3.1 & 0.6 \\
\hline
\end{tabular}

See Figure $1, A$, for schematic depiction of the parameters measured. All measurements $(A-I, \mathrm{~cm} / \mathrm{m}$, and $\mathrm{SD})$ of preoperative (T1), early postoperative (T2), and midterm follow-up postoperative (T3) echocardiographs in systole and diastole are shown.

\section{Left Atrioventricular Valve Annulus Area and Shape}

LAVV annulus area in systole and diastole increased significantly from the preoperative to the early postoperative period as measured by echocardiography $\left(4.1 \pm 0.2 \mathrm{~cm}^{2} /\right.$ $\mathrm{m}^{2}$ vs $6.1 \pm 0.3 \mathrm{~cm}^{2} / \mathrm{m}^{2}, P<.001$ in systole; $7.2 \pm 0.4$ $\mathrm{cm}^{2} / \mathrm{m}^{2}$ vs $10.0 \pm 0.5 \mathrm{~cm}^{2} / \mathrm{m}^{2}, P<.001$ in diastole, respectively, Figure $3, A$ ). This increase in LAVV annulus area was sustained in the midterm postoperative period.

The ratio $E / I$, which is an indicator of ellipsoid or circular nature of the LAVV annulus, was decreased in the early and midterm postoperative echocardiogram when compared with the preoperative echocardiogram (Figure 4), indicating that the LAVV annulus shape had changed from an elliptical to a more circular shape. This finding is also supported by the observation that much of the change in $C$ (the distance between right and left $\mathrm{AV}$ valve hinge points) occurred in the left component of the AV valve postoperatively. Thus, the annular remodeling postoperatively appeared to occur at the left $\mathrm{AV}$ free wall or the hinge point of the left lateral leaflet.

\section{Left Ventricular Volume and Vena Contracta Measurements}

LV volume indexed to BSA increased in the early and midterm postoperative echocardiograms compared with the preoperative echocardiogram $\left(16.9 \pm 1.2 \mathrm{~mL} / \mathrm{m}^{3}\right.$ vs $26.2 \pm 1.7 \mathrm{~mL} / \mathrm{m}^{3}, P<.001$ in systole; $35.0 \pm 2.4 \mathrm{~mL} / \mathrm{m}^{3}$ vs $52.5 \pm 3.2 \mathrm{~mL} / \mathrm{m}^{3}, P<.001$ in diastole). We did not detect any difference between the early and midterm postoperative echocardiograms $\left(26.8 \pm 1.7 \mathrm{~mL} / \mathrm{m}^{3}, P=.81\right.$ in systole; $51.1 \pm 2.5 \mathrm{~mL} / \mathrm{m}^{3}, P=.73$ in diastole). $\mathrm{LV}$ volume changes are shown in Figure 3, $B$.

Finally, we quantified the LAVV regurgitant jet using the diameter of the VC (Figure 5). The size of the LAVV VC was small at all time points for most patients and showed a slight but significant decrease in the postoperative compared with preoperative echocardiography studies $(0.2 \pm$ $0.01 \mathrm{~cm} / \mathrm{m}$ vs $0.3 \pm 0.01 \mathrm{~cm} / \mathrm{m}$, respectively, mean \pm standard error of the mean, $P<.001)$.

\section{DISCUSSION}

$\mathrm{AV}$ canal defects represent a complex set of congenital heart lesions characterized by a defect in the development of the endocardial cushions. The general principles of surgical repair of CAVC have changed little over the past few decades, with the primary goal being partitioning of the common $\mathrm{AV}$ valve and closing the atrial and ventricular communications. The only controversial part of the procedure has focused on the zone of apposition or cleft of the left AV valve. ${ }^{15}$ Current valvuloplasty techniques usually include closure of the cleft in the left $\mathrm{AV}$ valve with or without varying types of commissuroplasty or annuloplasty of the left AV valve. An annuloplasty is usually performed only if there is dilatation of the annulus to prevent postsurgical regurgitation. However, the technique for annuloplasty varies greatly and is often dictated by surgeon preference. The main goal of our study was to determine the changes in the various parameters of ventricular and annular geometry after CAVC surgery and to determine if this remodeling is sustained in the midterm postoperative period.

The most significant finding of our study was the nature of the LAVV annular remodeling after surgical repair of CAVC. There is a significant increase in indexed left AV valve diameter as measured in the septal to lateral wall dimension after surgical repair of CAVC. This increase occurred primarily as a consequence of lateral wall displacement rather than septal shift toward the right ventricle. The statement that the free wall circumference is increased rather than a septal shift is based on comparisons of distances between the septum and the right ventricle versus the septum and the LV free wall dimensions pre- and 
TABLE 2. Changes in parameters among the three time points

\begin{tabular}{|c|c|c|c|c|c|}
\hline \multicolumn{6}{|c|}{ Systole } \\
\hline & T1 vs T2 $(\mathrm{cm} / \mathrm{m})$ & & T1 vs T3 $(\mathrm{cm} / \mathrm{m})$ & & T2 vs T3 $(\mathrm{cm} / \mathrm{m})$ \\
\hline$A$ & $0.4( \pm 0.1), P<.001$ & $*$ & $0.5( \pm 0.1), P<.001$ & $*$ & $0.2( \pm 0.1), P=.14$ \\
\hline$B$ & $0.2( \pm 0.1), P=.08$ & & $0.4( \pm 0.1), P<.001$ & $*$ & $0.2( \pm 0.1), P=.06$ \\
\hline$C$ & $0.3( \pm 0.1), P=.025$ & $*$ & $0.3( \pm 0.2), P=.107$ & & $0.01( \pm 0.2), P=.98$ \\
\hline$D$ & $0.1( \pm 0.1), P=.12$ & & $0.3( \pm 0.1), P=.18$ & & $0.2( \pm 0.1), P=.14$ \\
\hline$E$ & $0.4( \pm 0.1), P<.001$ & $*$ & $0.4( \pm 0.1), P<.001$ & $*$ & $0.01( \pm 0.1), P=.88$ \\
\hline$F$ & $0.2( \pm 0.1), P=.089$ & & $0.4( \pm 0.1), P=.008$ & $*$ & $0.1( \pm 0.1), P=.35$ \\
\hline$G$ & $0.1( \pm 0.1), P=.26$ & & $0.4( \pm 0.1), P=.007$ & $*$ & $0.3( \pm 0.1), P=.057$ \\
\hline$I$ & $0.5( \pm 0.1), P<.001$ & $*$ & $0.5( \pm 0.1), P<.001$ & $*$ & $0.001( \pm 0.05), P=.9$ \\
\hline \multicolumn{6}{|c|}{ Diastole } \\
\hline & $\mathrm{T} 1 \mathrm{vs} \mathrm{T} 2(\mathrm{~cm} / \mathrm{m})$ & & T1 vs T3 $(\mathrm{cm} / \mathrm{m})$ & & $\mathrm{T} 2$ vs $\mathrm{T} 3(\mathrm{~cm} / \mathrm{m})$ \\
\hline$A$ & $0.7( \pm 0.1), P<.001$ & $*$ & $0.8( \pm 0.1), P<.001$ & $*$ & $0.1( \pm 0.1), P=.18$ \\
\hline$B$ & $0.2( \pm 0.1), P=.06$ & & $0.3( \pm 0.1), P=.02$ & $*$ & $0.1( \pm 0.3), P=.33$ \\
\hline$C$ & $0.5( \pm 0.1), P<.001$ & $*$ & $0.6( \pm 0.2), P<.005$ & $*$ & $0.1( \pm 0.1), P=.58$ \\
\hline$D$ & $0.1( \pm 0.1), P=.315$ & & $0.1( \pm 0.1), P=.313$ & & $0.17( \pm), P=.06$ \\
\hline$E$ & $0.5( \pm 0.1), P<.001$ & $*$ & $0.5( \pm 0.1), P<.001$ & $*$ & $0.02( \pm 0.1), P=.857$ \\
\hline$F$ & $0.5( \pm 0.1), P<.001$ & $*$ & $0.5( \pm 0.1), P<.001$ & $*$ & $0.01( \pm 0.1), P=.92$ \\
\hline$G$ & $0.006( \pm 0.1), P=.96$ & & $0.1( \pm 0.1), 0.35$ & & $0.1(0.1), P=.27$ \\
\hline$I$ & $0.6( \pm 0.05), P<.001$ & $*$ & $0.6( \pm 0.08), P<.001$ & $*$ & $0.01( \pm 0.08), P=.86$ \\
\hline
\end{tabular}

Summary of all the changes of the various measurements $(\mathrm{cm} / \mathrm{m})$ over time (T1 vs T2, T1 vs T3, and T2 vs T3) in systole and diastole, including $P$ values. $T 1$, Preoperative; $T 2$, early postoperative; $T 3$, midterm postoperative. *Statistically significant.

postoperatively. These indicate that posterior LV free wall circumference changes were observed rather than the former. The effect of this change is to make the LAVV more circular, displacing the lateral leaflet away from the composite leaflet, made up of the sutured inferior and superior left components of the bridging leaflets. This shift would tend to exacerbate any central regurgitant jet that may be present at the end of the original CAVC repair.
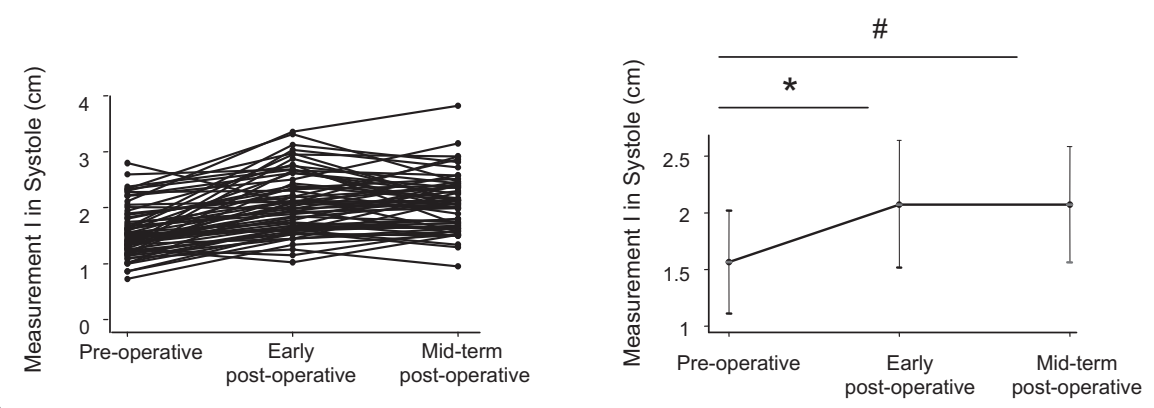

A
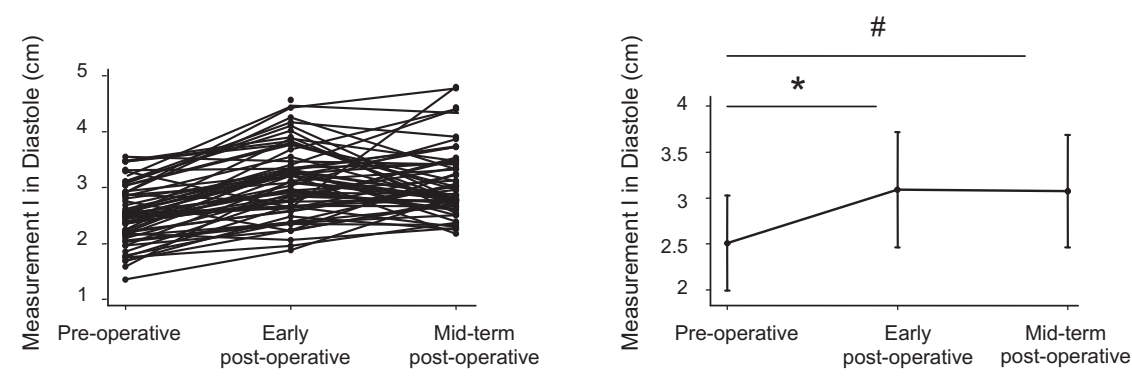

FIGURE 2. Measurement $I$, the distance between the septum and the lateral free wall of the left AV valve in the parasternal long-axis view, was significantly increased after surgical repair of CAVC both in systole (A) and diastole (B). This increase was evident in the early postoperative period $(0.5 \mathrm{~cm} / \mathrm{m}[95 \%$ confidence interval, $0.39-0.62]$ in systole and $0.6 \mathrm{~cm} / \mathrm{m}[95 \%$ confidence interval, $0.46-0.69]$ in diastole, $P<.001$; indicated with *) and was sustained in the midterm postoperative follow-up period. The increase in $I$ from preoperative to midterm postoperative period is $0.5 \mathrm{~cm} / \mathrm{m}(95 \%$ confidence interval, $0.37-0.63)$ in systole and $0.6 \mathrm{~cm} / \mathrm{m}(95 \%$ confidence interval, $0.39-0.74)$ in diastole. These increases are highly significant $(P<.001$; indicated with \#). 

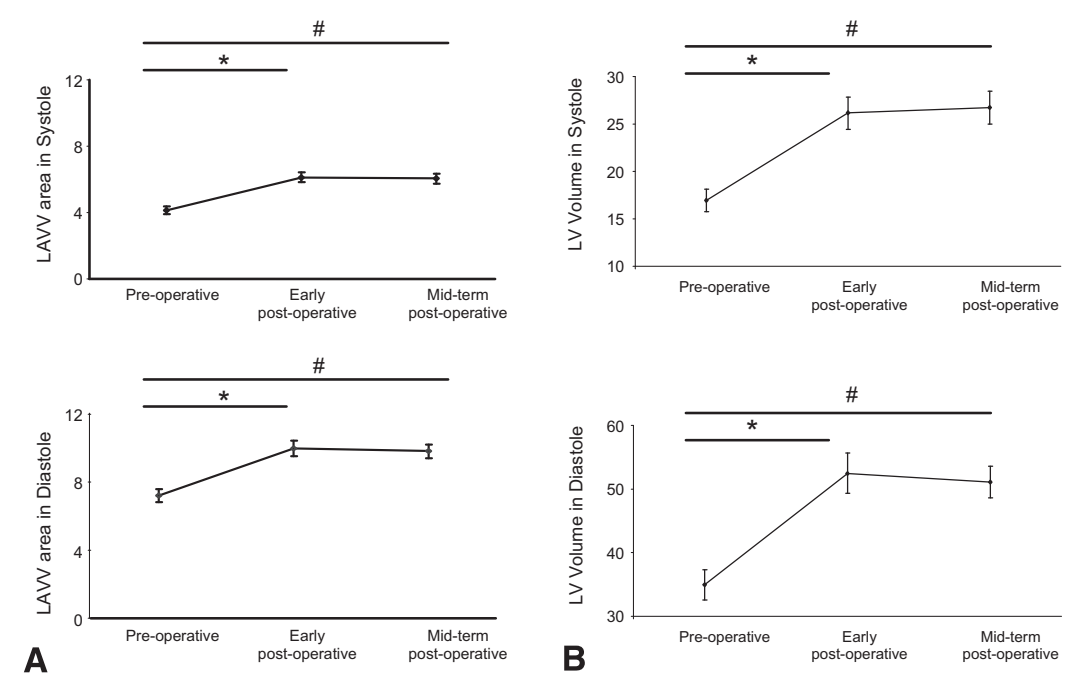

FIGURE 3. A, Increase in the LAVV annulus area in systole and diastole in the early postoperative period compared with the preoperative period (4.1 \pm 0.2 $\mathrm{cm}^{2} / \mathrm{m}^{2}$ vs $6.1 \pm 0.3 \mathrm{~cm}^{2} / \mathrm{m}^{2}, P<.001$ in systole, and $7.2 \pm 0.4 \mathrm{~cm}^{2} / \mathrm{m}^{2}$ vs $10 \pm 0.5 \mathrm{~cm}^{2} / \mathrm{m}^{2}, P<.001$ in diastole; indicated with *, respectively). This increase in LAVV annulus area was sustained in the midterm postoperative period $\left(6.1 \pm 0.3 \mathrm{~cm}^{2} / \mathrm{m}^{2}, P=.85\right.$ in systole, and $10 \pm 0.4 \mathrm{~cm}^{2} / \mathrm{m}^{2}, P=.78 \mathrm{in}$ diastole). \#The statistically significant increase in LAVV annulus area in systole and diastole in midterm postoperative period compared with the preoperative period. $\mathrm{B}$, Increase of the LV volume in the early and midterm follow-up postoperative echocardiogram in systole and diastole compared with the preoperative echocardiogram $\left(16.9 \pm 1.2 \mathrm{~mL} / \mathrm{m}^{3}\right.$ vs $26.2 \pm 1.7 \mathrm{~mL} / \mathrm{m}^{3}, P<.001$ in systole, and $35 \pm 2.4 \mathrm{~mL} / \mathrm{m}^{3}$ vs $52.5 \pm 3.2 \mathrm{~mL} / \mathrm{m}^{3}, P<.001$ in diastole; as indicated with * and \#, respectively). $L A V V$, Left atrioventricular valve; $L V$, left ventricular.

Before surgical repair, pressures in both ventricles are equal, in contrast with the postoperative pressures where right ventricular systolic pressure should be substantially
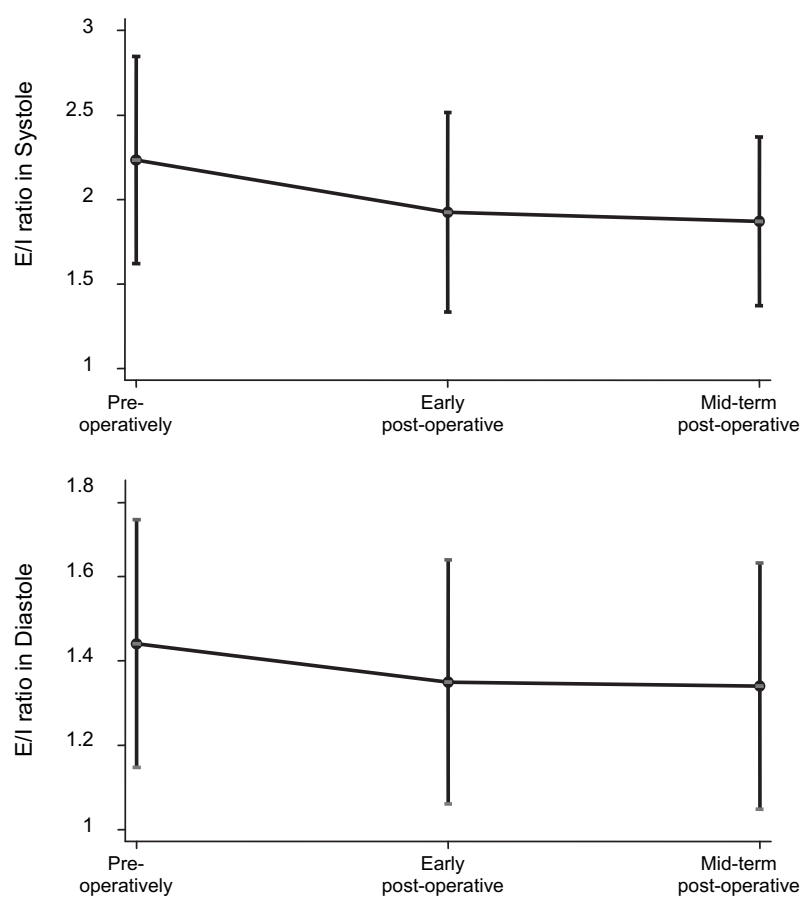

FIGURE 4. Ratio of the $E / I$, which was used as an indicator of ellipsoid or circular nature of the LAVV annulus. The ratio $E / I$ was decreased in the early and midterm postoperative echocardiogram compared with the preoperative echocardiogram, which indicates a more circular nature of the postoperative LAVV annulus. lower than LV pressure. This would lead us to believe that the annular remodeling would occur by a shift in the ventricular septum after surgery with the dimensions of the right component of the AV valve decreasing. However, we noted in our study that the annular shift occurred toward the left $\mathrm{AV}$ free wall rather than changes in the relative poss on a more circular shape when compared with the elliptical shape oriented with the long axis parallel to the septum before repair. This is an important finding because it can help determine the type of annuloplasty that needs to be performed if these valves need further intervention or potentially as a preventive measure to avoid progression of regurgitation after surgery.

In regard to the implications of this study for the surgeon and surgical technique, the goal of this study was to describe the geometric changes in AV valve orifice that occur after repair of CAVC. These changes were independent of the surgical technique used for ventricular septal defect/atrial septal defect closure, but the valve orifice changes do have implications for the leaflet repair, because the valve orifice needs to be completely covered by valve tissue in systole to achieve valve competence. Our findings have implications for the surgical technique for partitioning the common $\mathrm{AV}$ valve. We postulate that these changes in annular geometry can contribute to the development of residual LAVV regurgitation after surgical repair if the surgeon does not consider them in deciding how to partition the available AV valve leaflet tissue.

As expected, the LAVV regurgitation, as measured by the $\mathrm{VC}$, was decreased in the majority of infants after surgical repair, and this decrease was sustained in the midterm 


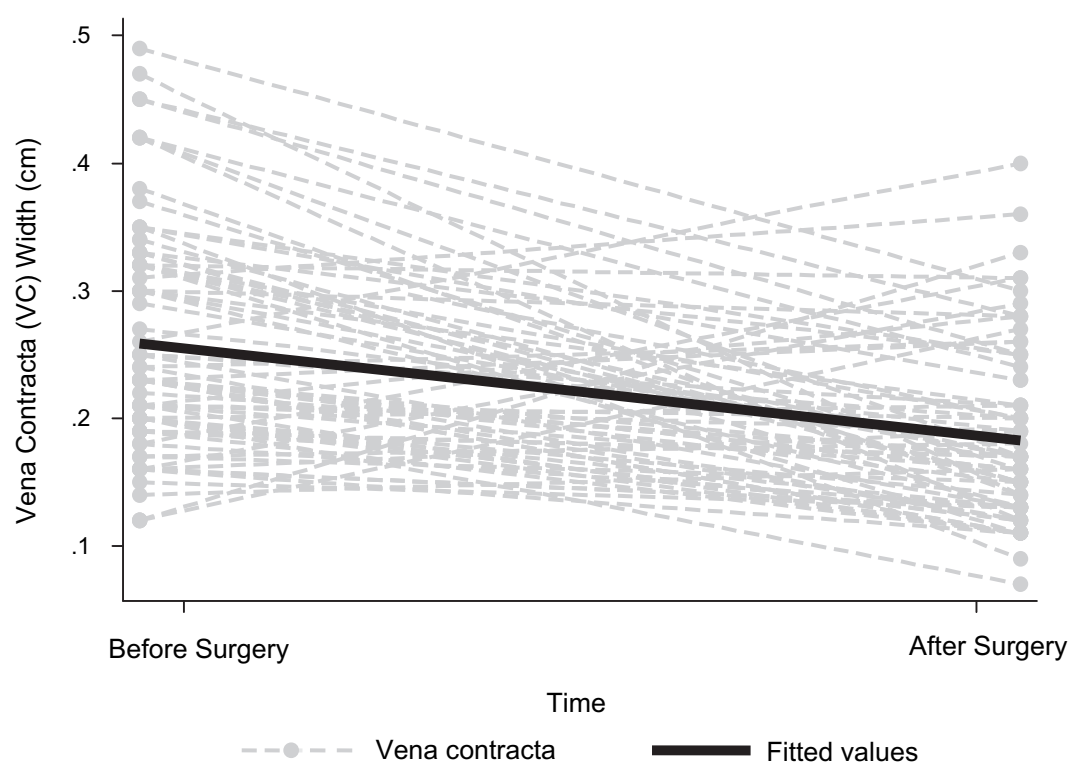

FIGURE 5. LAVV regurgitant jet of all 101 patients was estimated using the diameter of the VC in the apical 2-chamber view using color Doppler flow. The LAVV VC decreases in the postoperative echocardiogram when compared with the preoperative echocardiogram $(0.2 \pm 0.01 \mathrm{~cm} / \mathrm{m} \mathrm{vs} 0.3 \pm 0.01 \mathrm{~cm} / \mathrm{m}$, $P<.001)$

postoperative period. We believe this is related primarily to the extent of LAVV leaflet coaptation left after repair and cleft closure. However, when leaflet coaptation is minimal, resulting in more than mild regurgitation early after surgery, the annular remodeling that occurs may rapidly worsen the regurgitation. According to our findings, posterior annuloplasty of the left AV valve may prevent the adverse remodeling, stabilizing the regurgitation for a time.

\section{Study Limitations}

First, the echocardiographic data used were not all obtained at one core laboratory. Although we made every effort to perform the studies at our center, some of the studies were performed at outside institutions. However, we did review all of the studies ourselves and attempted to match the views with those obtained at our center. Second, the 2D echocardiography data can only help us draw limited conclusions about the 3-dimensional annulus because the annulus is saddle-shaped normally and even more pronounced in canal defects. However, changes in planar dimension accurately depict the major valve changes with surgery because the valve leaflets still have to cover the orifice in systole, and a change to a more circular valve orifice will lead to incomplete coverage by the available leaflet tissue. Further studies performed using 3-dimensional echocardiography would help determine the true nature of LAVV annular remodeling. An advantage of 3-dimensional $\mathrm{VC}$ area as an index of LAVV regurgitation would be its accuracy in clinically significant regurgitation. ${ }^{16}$ However, several studies show that the VC width is a useful tool for quantification of LAVV regurgitation, and these results provide crucial preliminary data for development of further studies. Third, 141 patients who underwent CAVC repair during the time frame of this study were not eligible for data interpretation because they did not have echocardiograms at all 3 data points and therefore had to be excluded. This is a limitation of this retrospective study, and we have acknowledged this in the article. However, the series is large and the operative mortality rate low enough that the patient cohort with complete echocardiography data is likely representative of the larger population. The current study provides important preliminary data for designing further studies aimed at analyzing annular remodeling after CAVC repair.

\section{CONCLUSIONS}

This study analyzed the changes in AV valve geometry in a large cohort of infants undergoing repair of CAVC. The left AV valve undergoes significant enlargement early after surgery, which is sustained in midterm follow-up. The major geometric changes were a more circular shape to the left $\mathrm{AV}$ valve with an increase in the septal to free wall dimension. This change in geometry may adversely affect AV valve regurgitation present early after surgery.

\section{References}

1. Jahnke EJ. Surgical management of atrioventricular canal. Am Surg. 1969;35 59-66.

2. Lillehei CW, Cohen M, Warden HE, Varco RL. The direct-vision intracardiac correction of congenital anomalies by controlled cross circulation; results in thirty-two patients with ventricular septal defects, tetralogy of Fallot, and atrioventricularis communis defects. Surgery. 1955;38:11-29.

3. Tweddell JS, Litwin SB, Berger S, Friedberg DZ, Thomas JP, Frommelt PC, et al. Twenty-year experience with repair of complete atrioventricular septal defects. Ann Thorac Surg. 1996;62:419-24. 
4. Sellke FW, Del Nido PJ, Swanson SJ. Atrioventricular canal defects. In: Mora BM, Daebritz SH, del Nido PJ, eds. Sabiston and Spencer's Surgery of the Chest. Volume 2, 7th ed. Philadelphia: Elsevier; 2005:1959-78.

5. Alexi-Meskishvili V, Ishino K, Dahnert I, Uhlemann F, Weng Y, Lange PE, et al. Correction of complete atrioventricular septal defects with the double-patch technique and cleft closure. Ann Thorac Surg. 1996;62:524-5.

6. Meisner H, Guenter T. Atrioventricular septal defect. Pediatr Cardiol. 1998;19: 276-81.

7. Thies WR, Breymann T, Matthies W, Crespo-Martinez E, Meyer H, Korfer R. Primary repair of complete atrioventricular septal defect in infancy. Eur J Cardiothorac Surg. 1991;5:571-4.

8. Moran AM, Daebritz S, Keane JF, Mayer JE. Surgical management of mitral regurgitation after repair of endocardial cushion defects: early and midterm results. Circulation. 2000;102(Suppl 3):III160-5.

9. Rhodes J, Warner KG, Fulton DR, Romero BA, Schmid CH, Marx GR. Fate of mitral regurgitation following repair of atrioventricular septal defect. Am J Cardiol. 1997;80:1194-7.

10. Abbruzzese PA, Napoleone A, Bini RM, Annecchino FP, Merlo M, Parenzan L. Late left atrioventricular valve insufficiency after repair of partial atrioventricular septal defects: anatomical and surgical determinants. Ann Thorac Surg. 1990;49:111-4.
11. Michielon G, Stellin G, Rizzoli G, Casarotto DC. Repair of complete common atrioventricular canal defects in patients younger than four months of age. Circulation. 1997;96(Suppl):II-316-22.

12. Bando K, Turrentine MW, Sun K, Sharp TG, Ensing GJ, Miller AP, et al. Surgical management of complete atrioventricular septal defects. A twenty-year experience. J Thorac Cardiovasc Surg. 1995;110:1543-52.

13. Sluysmans T, Colan SD. Theoretical and empirical derivation of cardiovascular allometric relationships in children. J Appl Physiol. 2005;99:445-57.

14. Lang RM, Bierig M, Devereux RB, Flachskampf FA, Foster E, Pellikka PA, et al. Recommendations for chamber quantification: a report from the American Society of Echocardiography's Guide and Standards Committee and the Chamber Quantification Writing Group, developed in conjunction with the European Association of Echocardiography, a branch of the European Society of Cardiology. $J$ Am Soc Echocardiogr. 2005;18:1220-53.

15. Calabro R, Limongelli G. Complete atrioventricular canal. Orphanet J Rare Dis. 2006;5(1):8.

16. Little SH, Pirat B, Kumar R, Igo SR, McCulloch M, Hartley CJ, et al. Threedimensional color Doppler echocardiography for direct measurement of vena contracta in mitral regurgitation. JACC Cardiovasc Imaging. 2008;1: 695-704. 